Research Paper:

\title{
Effect of Discharge Planning on Metabolic Factors in crossiark Type 2 Diabetic Patients
}

\author{
Alemeh Dehnabi ${ }^{1} \odot$, Hassan Navipour ${ }^{1 *}$, Hamid Radsepehr ${ }^{2}$, Musa al- Reza Tadayonfar ${ }^{3}$ \\ 1. Department of Nursing, School of Medical Sciences, Tarbiat Modares University, Tehran, Iran. \\ 2. Center of Counseling and Mental Health of Students, Sabzevar University of Medical Sciences, Sabzevar, Iran. \\ 3. Department of Nursing, Faculty of Nursing and Midwifery, Sabzevar University of Medical Sciences, Sabzevar, Iran.
}

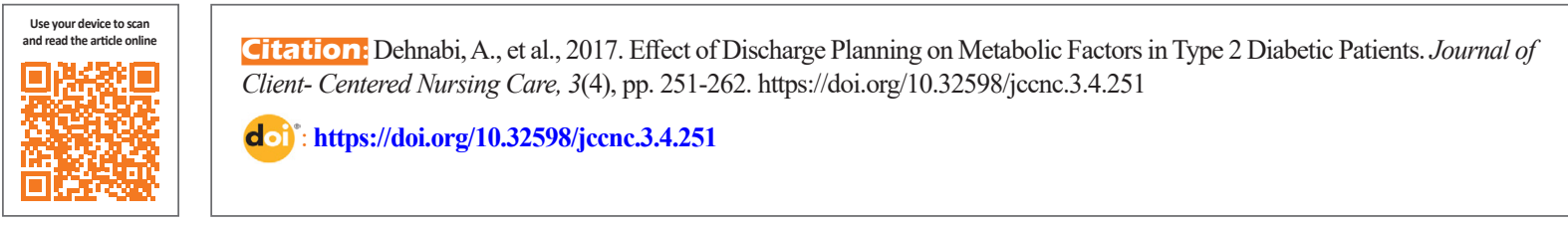

Article info:

Received: 26 Feb 2017

Accepted: 03 Jul 2017
Keywords:

Discharge planning, Metabolic factors, Diabetes type II, Nurse

\section{A B S T R A C T}

Background: Diabetes is one of the main causes of mortality in both the developed and developing countries (e.g. Iran). It can lead to serious consequences, such as fatigue, paralysis as well as financial burden for the health system and the patients. In this research, we are going to consider the effect of discharge planning program on metabolic factors in type 2 diabetic patients.

Methods: The present study is a quasi- experimental research. The samples consisted of 70 patients with type II diabetes, who were admitted to Vasei hospital in Sabzevar- Iran. The samples were selected using the convenience sampling method. Discharge planning was carried out by researchers based on the nursing process in two stages: before and after discharge. The followup process continued for four months after the patients' discharge. Data collection instruments consisted of check list, medical measurement devices, sphygmomanometer, and blood test to measure metabolic factors (glycosylated hemoglobin, triglyceride, high- density lipoprotein, systolic and diastolic blood pressure and waist circumference). Data was analyzed by pair $t$ test independent t-test, and chi-square using SPSS-PC (V.20).

Results: There was a statistically significant difference between the intervention and the control group, taking into account the average systolic blood pressure $(\mathrm{P}=0.002)$, glycosylated hemoglobin $(\mathrm{P}<0.0001)$, and triglycerides level $(\mathrm{P}=0.02)$. However, no statistically significant difference was observed in the mean score $\operatorname{HDL}(\mathrm{P}=0.69)$, diastolic blood pressure $(\mathrm{P}=0.3)$ and waist size $(\mathrm{P}=0.46)$.

Conclusion: According to the findings, one may conclude that the discharge planning has led to the improvement of some of the metabolic factors (glycosylated hemoglobin, triglyceride, systolic blood pressure) among the diabetic patients.

\footnotetext{
* Corresponding Author:

Hassan Navipour, PhD

Address: Department of Nursing, School of Medical Sciences, Tarbiat Modares University, Tehran, Iran.

Tel: +98 (936) 1448149

E-mail: naviporh@modares.ac.ir
} 


\section{Background}

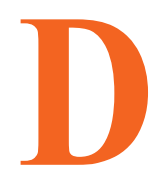

iabetes mellitus refers to a set of chronic metabolic conditions which is determined by increased blood sugar levels due to the body's inability to produce enough insulin or due to its insulin resistance (American Diabetes Association 2006). World Health Organization (WHO) has anticipated that the number of type 2 diabetic patients will increase by over $50 \%$ within the next 10 years and diabetes will be known as the seventh major cause of death in the world by 2030 (World Health Organization 2014). One of the major reasons why governments are paying attention towards diabetes is its ability to cause serious complications including eye and kidney diseases, innervation disorders, diabetic foot, non- traumatic amputation and atherosclerosis (Dyck et al. 2010). Heart disease account for $65 \%$ of mortality and diabetic patients are at 2- 4 times more likely to suffer from heart diseases than the no- diabetic. In addition, high- density lipoprotein dysfunction has been observed in patients with type 2 diabetes (Besler, Lüscher \& Landmesser 2012). More than $70 \%$ of diabetic patients are diagnosed with hypertension and are treated with blood pressure medications. Moreover, about $15 \%$ to $25 \%$ of diabetic patients have experienced amputation throughout their life; that is, they are at 10- 20 times risk as compared to normal people (Deshpanda, Harris- Hayes \& Schootman 2008). More than 80,000 cases of amputations are caused by severe ulceration of feet in diabetic patients in the US per year. The annual cost of treatment for each foot ulceration comes around $\$ 8,000$ in average; if the wound gets infectious, it costs around $\$ 17,000$, while it costs around $\$ 45,000$ for ulcers causing amputation. Therefore, diabetes imposes great costs on the economy of the society (Derosa, Salvadeo \& Cicero 2006).

Instability of blood glucose, blood pressure, and probably, lipid profile can be detrimental to the health of diabetic patients. A systematic review has shown that glucose variability can be a predictive factor for diabetic retinopathy, cardiovascular diseases and the mortality rate in patients with type 3 diabetes. These reports accentuate the significance of preventing considerable changes in blood pressure and blood sugar in diabetic patients (Nalysnyk, Hernandez- Medina \& Krishnarajah 2010). Research has shown that lowering high blood sugar and high cholesterol can reduce the complications of diabetes. One percent reduction in glycosylated hemoglobin reduces microvascular complications by $40 \%$ and serum lipid control can reduce cardiovascular complications by $20 \%$ to $50 \%$ (Deshpanda, Harris- Hayes \& Schootman 2008). Raising the awareness among diabetic patients about var- ious complications and symptoms of diabetes, self- care principles and continuous control of blood sugar as close to normal range, may prevent the occurrence of early and late complications of diabetes, ensure long life for the patient and reduce healthcare costs (Mahmoudi 2006).

Hospital discharge is a complicated and challenging process for professional staffs, patients and the caregivers. An effective discharge planning can significantly increase the patients' health and reduce their readmission to the hospitals (Phillips et al. 2004). Rorden and Taft define discharge planning as a multi- staged preparation process including immediate objectives in order to predict changes in the patient's care needs as well as long- term objectives in order to ensure the continuity of health care (Rorden \& Taft 1990). Discharge planning is an important principle in patients' need analysis during hospitalization in order to determine the continuity of care after discharge (Yam et al. 2010). This process may include physical and psychological assessment, training and consulting the patients and their family or caregivers, providing referrals and coordinating with other members of medical team, and follow- ups for evaluating discharge program (Watts $\&$ Gandner 2005). Studies have shown that increased readmission in the US can be due to following issues: unfavorable assessment of discharge by the patient, imperfect discharge program, difficulty in communication and information transfer between the hospital doctors and the society, insufficient care and follow- ups after discharge or a combination of these processes (Philbin 1999).

As patients' needs are increasing and getting more complicated, it is important to establish an effective discharge planning system in order to identify and respond to different needs of the patients for better coordination and care after discharge (Department of Human Services 1998). Indeed, discharge program starts from the very beginning of admission when information about the patient is collected and recorded. Discharge program is a regular and systematic process which is planned in order to prepare the patients for leaving the medical care unit and maintain the continuity of care. The key to the success of discharge program is linked to information transfer between the patient, caregivers and hospital staffs who are responsible for taking care of the patient, both during his/her hospitalization in the medical care unit and his/her return to home. Creating such coordination for taking care of patients is the responsibility of nurses. The nurse should ensure that necessary information and skills are given and taught to the patient's family members and they refer also the patient to medical care centers or social services to assist the patient while at home (Taylor 2003). Therefore, discharge planning system is 
crucial for both the patient and the caregiver in order to facilitate continuous management and provide predictable and unpredictable cares in future (Bauer at al. 2009).

The outcomes of this program include reducing the length of hospitalization and readmission, increasing the accessibility of health services after hospitalization, increasing the satisfaction of discharged patients, and improving the quality of life and continuity of care (Marks 1994). However, despite the fact that discharge program is the key component that defines the role of the nurses, it is often neglected due to the lack of time (Atwal 2002).

Self- care education has been given to the patients in different patterns, most of which are unknown to the nursing experts; thus, it requires a comprehensive planning to acquaint the nursing personnel with how to use these patterns in clinical practice. Consequently, the present research planned a discharge program based on the nursing process assuming that most of the nurses are acquainted with the intended process, and subsequently, aimed at evaluating the effect of the proposed discharge program on controlling the metabolic factors of patients with type 2 diabetes.

\section{Materials and Methods}

\section{Study design}

This research is a quasi- experimental study. The registration code is 2211315 . The Code of Ethics was registered in December 2013 with the number D52/4974 by the Ethics Committee of Tarbiat Modares University. Participants were placed through non- random method in both the intervention and control groups. The intervention group received discharge planning after hospitalization and was then followed up for four months after discharge. The intervention and control groups were compared after four months.

\section{Population study and procedure}

The study was conducted in Sabzevar over a period of 12 months. The target population consisted of patients with type 2 diabetes, who were referred to the Vasei hospital. Inclusion criteria included at least two years of diagnosis with type 2 diabetes and treated with hypoglycemic drugs, have a healthy hearing power, the ability to read and write, living in Sabzevar and not participating in any diabetes education program during the study. Exclusion criteria included catching hyperglycemic hyperosmolar non- ketonic syndrome, cognitive impairment, and kidney and liver failure. According to the central limit theorem and taking into account the average effect size
(0.5) in accordance with the Cohen table and the power of $0.8,32$ diabetic subjects were considered for each group. With a $10 \%$ attrition rate, three were added to each group and a total of 70 subjects were selected (35 control and 35 intervention group). In this way, considering the possibility of re- admission of patients and the presence of only one internal department in the hospital, in order to prevent the bias of research, the control group was first selected by convenience sampling. After the completion of the control group, the intervention group was selected. At the start, researchers assessed the eligibility of subjects by visiting the emergency department and collecting informed consent form that was signed by the participants.

\section{Intervention}

Measurement of demographic and basic data (Systolic and diastolic blood pressure, waist size, Glycosylated hemoglobin, triglycerides and high- density lipoprotein) was performed at the beginning of hospitalization. The intervention group was asked to participate in the discharge planning that was followed for four months while the control group was received routine services. However, the training package was given to the control group after the study.

Participants were followed for over four months later by the researcher to collect information and data relating to the post- test. Metabolic factors (blood pressure, waist size, glycosylated hemoglobin, triglycerides and highdensity lipoprotein) were measured in both groups at the end of follow- up.

The study measured the impact of discharge planning on metabolic factors of patients (blood pressure, waist size, glycosylated hemoglobin, triglycerides and highdensity lipoprotein). Discharge planning algorithm is shown in Figure 1.

Discharge planning was implemented from the time of patient admission to the internal ward and metabolic factors were measured in two stages.

A: The first stage (24 hours after admission and hospitalization in internal ward) in which discharge planning process was initiated based on the nursing process for patients in internal ward. This stage includes Assessment, Nursing diagnosis, Planning, Implementation.

The first stage was the assessment phase in which interviews were conducted and training needs assessment of patients and households and food frequency questionnaire were determined. 

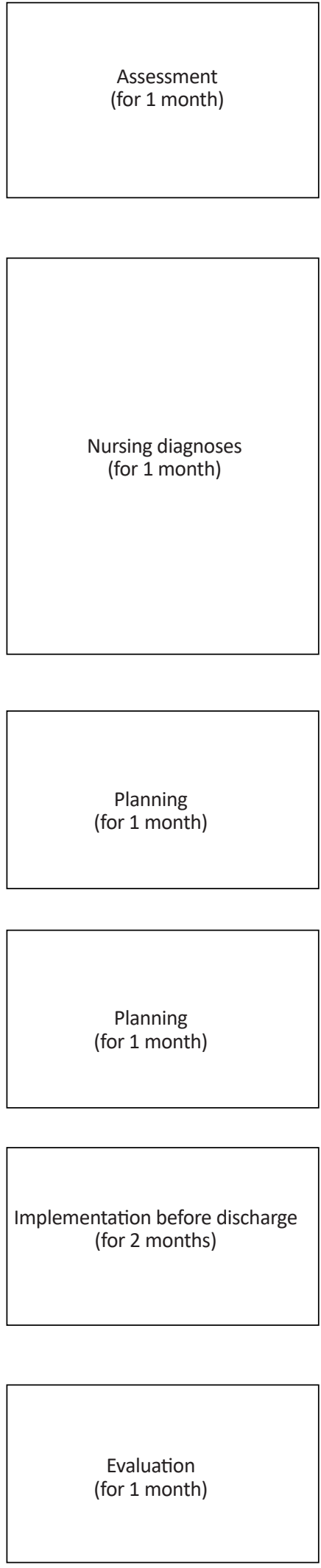

- Decreased self- care and lack of diet information in diabetic patients

- Self- care reduction in physical activity and exercise

- Lack of information on the pharmaceutical and non- pharmaceutical diet

- Reduced self- care due to lack of self- care skills (lack of glucose control, insulin- induced lipodystrophy)

- Lack of information about diabetes

- Lack of information on methods for controlling and preventing disease complications

Need to:

- Having enough information about diabetes nutrition and diabetes self- care skills in relation to the lack of specific information resources with an unsuitable diet (about $63 \%$ of all diagnoses) - Performing appropriate activity in relation to the lack of awareness of the role of exercise in the treatment of type 2 diabetes Characterized by mobility less than 1 hour per week ( $22 \%$ of total diagnosis)

- Having enough information about blood glucose control drugs and self- care skills in insulin infusion due to lack of specific information resources with insufficient correct injections of insulin and adjustment of dose and improper use of oral medication (15\% of total diagnosis)

- Self- care skills in the field of blood glucose control in relation to the lack of access to the blood glucose control device and the lack of specific information resources due to the inability to control blood glucose and the expression of blood glucose ( $13 \%$ of all diagnoses)

- Having sufficient information about the nature of diabetes and its complications in relation to the lack of specific information resources, with the absence of the nature of the disease, and at least 3 of the complications of diabetes ( $7 \%$ of the total diagnosis)

- Education standards of diabetes nutrition (foods authorized and unauthorized)

- Training standards for exercise and activities in a diabetic patient (daily walking program and necessary measures before starting exercise)

- Drug use standards (pre- meal and drug attention)

- Training standards for insulin injections and blood glucose control (insulin injection site, appropriate syringe, insulin units)

- Education standards of diabetes nutrition (foods authorized and unauthorized)

- Training standards for exercise and activities in a diabetic patient (daily walking program and

necessary measures before starting exercise)

- Drug use standards (pre- meal and drug attention)

- Training standards for insulin injections and blood glucose control (insulin injection site, appropriate syringe, insulin units)

- Understanding diabetes

- Practical training glycemic control

- Nutrition in diabetes

- Sports Suitable for diabetes

- Injection insulin

- Medication in diabetes

- Questions and answers from participants

- Monitor the implementation of techniques

- Assess self- report checklists 
Table 1. Walking schedule for type 2 diabetic patients

\begin{tabular}{ccc}
\hline Week & Number of Sessions Per Week & Duration of Each Session \\
\hline First & $3-5$ Times & 10 Minutes \\
\hline Second & $3-5$ Times & 15 Minutes \\
\hline Third & $3-5$ Times & 20 Minutes \\
\hline Fourth & $3-5$ Times & 25 Minutes \\
\hline Fifth & $3-5$ Times & 30 Minutes \\
\hline Sixth & $3-5$ Times & 35 Minutes \\
\hline Seventh & $3-5$ Times & 40 Minutes \\
Eighth & $3-5$ Times & 45 Minutes \\
Ninth time later & $3-5$ Times & This program is repeated \\
\hline
\end{tabular}

In nursing diagnosis stage, after collecting the information, nursing diagnoses were made in the areas of nutrition, exercise, and medication, which is as follows: Having enough information about diabetes nutrition and diabetes self- care skills in relation to the lack of specific information resources with an unsuitable diet (about $63 \%$ of all diagnoses); Performing appropriate activity in relation to the lack of awareness of the role of exercise in the treatment of type 2 diabetes, which is characterized by mobility of less than 1 hour per week ( $22 \%$ of total diagnosis); Having enough information about blood glucose controlling drugs and self- care skills in insulin infusion due to lack of specific information with insufficient correct injections of insulin and adjustment of dose and improper use of oral medication (15\% of total diagnosis); Self- care skills in the field of blood glucose control in relation to the lack of access to the blood glucose control device and the lack of specific information resources due to the inability to control blood glucose and the expression of blood glucose ( $13 \%$ of all diagnoses); and Having sufficient information about the nature of diabetes and its complications in relation to the lack of specific information resources, in the absence of the nature of disease, and at least three of the complications of diabetes ( $7 \%$ of the total diagnosis).

Then, based on the collected information, nursing diagnoses was started discharge planning and training sessions for the patients.

In planning stage, according to the adjusted program and depending on the level of learning and training needs of the patients, self- care education and regular walking program were conducted in six sessions for each patient and each session lasted for 45-30 minutes (Table 1).
In implementation stage, discharge planning began from the time of patient admission and continued until two months after discharge from the hospital. At this stage, the previously designed step program was implemented (Table 2). Discharge planning was performed individually and collectively for all patients. In total, the care program was organized in three groups of four persons, two groups of three persons and five groups of two persons. Seven patients received the training individually. Meetings were held once or twice a day in the morning and afternoon in the patient's room or conference hall. At the beginning of each session, feedback was taken for the content and previous training session in various ways (questions and answers, and application).The results were transmitted to the patients. In order to assist the patients and encourage them to adhere to the training program, at the end of each training session, the discharge planning was presented in the form of self - care program for patient education booklet. Its content included the contents of the training sessions that had been taken from the Iranian Association for Diabetes and had been approved by the internal medicine specialist. It should be noted that in all the meetings, a member of the family who lived with the patient was also present.

On the discharge day, all contents were reviewed briefly in the presence of the patient and his/her family and were placed in the patient's training package. The package included the training booklet, phone numbers of the researcher, checklists, self- report of the type and amount of daily food intake, daily physical activity, and consumption process of drugs. The checklist was provided to patients for a two- weeks period. In addition, if necessary, after the patient's discharge, visits to his or her 
living environment and educational needs were adjusted in accordance with his or her living conditions.

B: Second stage (after patient discharge from the hospital) in which after discharge, the follow- up period was divided into two two- month period. During the first two months after discharge, the patients were followed up with a phone call once a week and the visits were made every two weeks. In the second two- months period after discharge, the subjects contacted the researcher in the event of a problem or were referred to the hospital, after which the researchers also collected a checklist every three weeks and put the new checklist for the subjects. Self- reporting checklist was prepared on a weekly basis on the control form that included food intake of the patient, the patient's physical activity and the state of use of the drug at home. The forms were provided to the patients by the researcher who visited the patient's home. At the end of the 4- months follow- up after discharge, the metabolic factors were measured again.

\section{Data collection}

Demographic and clinical data were collected using a questionnaire that was designed for this study. The information was collected related to the metabolic factors, which are as follows: The researcher used a sphygmomanometer ALPK2. After calibration, internal correlation coefficients were calculated for blood pressure. After selecting 10 patients, their blood pressure was measured by the researcher and his colleague and the coefficient of correlation between them was calculated. The internal correlation coefficient systolic blood pressure was 0.91 and diastolic blood pressure was 0.84 . The waist circumference coefficient was estimated to be 0.87 . All measurements were performed in one day and at two turns in the morning and evening. Finally, the average value was calculated. In the next stage of intervention, the researcher used the previous device to measure again.

Blood tests: Blood samples of CBC and clot were taken from the patient in the morning shift of the weekly

Table 2. Description of training sessions

\begin{tabular}{|c|c|c|c|}
\hline $\begin{array}{l}\text { Contents } \\
\text { Sessions }\end{array}$ & Title & Training Method & $\begin{array}{l}\text { Evaluation } \\
\text { Method }\end{array}$ \\
\hline First & $\begin{array}{c}\text { Familiarity with } \\
\text { diabetes }\end{array}$ & $\begin{array}{l}\text { Face to face training using Power Point and video programs during a } 45-30 \\
\text { minutes session in the presence of active members of the family. It was about } \\
\text { the nature of the disease, acute complications of diabetes (hypoglycemia and } \\
\text { hyperglycemia), chronic complications of diabetes, symptoms, risk factors and } \\
\text { methods for preventing and treating them, diagnostic tests for type } 2 \text { diabetes }\end{array}$ & $\begin{array}{l}\text { Oral questions } \\
\text { at the end of the } \\
\text { meeting }\end{array}$ \\
\hline Second & $\begin{array}{l}\text { Practical train- } \\
\text { ing on blood } \\
\text { glucose control }\end{array}$ & $\begin{array}{l}\text { Face to face training in a } 30-45 \text { minutes session, in the presence of active } \\
\text { members of the family. Trained on using a glucometer that was carried out by } \\
\text { the researcher on how to control blood glucose. Then repeated and practiced } \\
\text { by the patient. }\end{array}$ & $\begin{array}{l}\text { Investigator's su- } \\
\text { pervision of blood } \\
\text { glucose control by } \\
\text { the patient }\end{array}$ \\
\hline Third & $\begin{array}{c}\text { Nutrition in } \\
\text { diabetes }\end{array}$ & $\begin{array}{c}\text { Face to face training using Power Point during a 45-30- minutes session in the } \\
\text { presence of a family member and training on the need for calories, calorie } \\
\text { distribution, food pyramid guidance, nutritional labels, cooking training for } \\
\text { type } 2 \text { diabetic patient in the form of educational videos and presentation of a } \\
\text { cookbook }\end{array}$ & $\begin{array}{l}\text { Oral questions } \\
\text { at the end of the } \\
\text { meeting }\end{array}$ \\
\hline Fourth & $\begin{array}{l}\text { Fitness for } \\
\text { diabetics }\end{array}$ & $\begin{array}{c}\text { Face to face training using Power Point during a } 45-30 \text { minutes session in } \\
\text { the presence of an active member of the family; teaching the importance of } \\
\text { exercise in diabetes, recommendations for exercise, exercise precautions, and } \\
\text { weekly walking schedule. }\end{array}$ & $\begin{array}{c}\text { Oral questions } \\
\text { at the end of the } \\
\text { meeting }\end{array}$ \\
\hline Fifth & Insulin infusion & $\begin{array}{l}\text { Face to face training during a 30-45 minutes session in the presence of active } \\
\text { members of the family, using syringes, insulin vials, injection pillows, insulin } \\
\text { types, insulin injection sites, insulin injections and insulin injections to himself/ } \\
\text { herself. Initially performed by the researcher for the patient. After ensuring } \\
\text { that the patient was familiar with all stages, insulin injections were injected on } \\
\text { the cushion by the researcher, and then repeatedly practiced by the patient. } \\
\text { Subsequently, insulin injections were initially performed with the help of the } \\
\text { researcher and after assurance without assistance. }\end{array}$ & $\begin{array}{l}\text { The investigator's } \\
\text { supervision of the } \\
\text { patient's correct } \\
\text { insertion and injec- } \\
\text { tion of insulin }\end{array}$ \\
\hline Sixth & $\begin{array}{l}\text { Drug therapy in } \\
\text { diabetes }\end{array}$ & $\begin{array}{l}\text { Face to face training using Power Point during a } 45-30 \text { minutes session, in the } \\
\text { presence of the active member of the family, the correct way of taking medica- } \\
\text { tions (oral or injectable, time, etc.),type and mechanism of medication, the } \\
\text { correct dose and its major complications (hypoglycemia and hyperglycemia, } \\
\text { etc.) to the patient, as well as the presentation of samples of the checklist and } \\
\text { an explanation of how to fill them. }\end{array}$ & $\begin{array}{c}\text { Oral questions } \\
\text { at the end of the } \\
\text { meeting }\end{array}$ \\
\hline
\end{tabular}


days and sent to the lab. Patients' blood was tested by biochemical analyzer Biotecinica Italy with automatic method using special kits (Pars test kits) and cell counter Sysmex Japan with solutions MAN Company. For trust and stability in laboratory measurements, experiments were carried out by a specialist in the laboratory. The results to the experiments were collected by the researcher on the day they were sent.

\section{Data analysis}

Descriptive and analytical statistics were used to analyze the data. The data were determined for central and dispersion measures. Normal distribution of data was found from Kolmogorov- Smirnov test. To compare, the average preand post- intervention in each group (test group and control group), pair $\mathrm{t}$ test was used. For the comparison of quantitative parameters between the two groups Independent ttest was used. To compare quality parameters between the two groups chi- square test was used. Equivalence groups based on demographic characteristics was performed using chi- square for continuous data and $t$ tests for discrete data. According to Cohen table, the effect size was considered average (0.5). There was no statistically significant difference between the two groups in terms of the above features. The significance level was considered at 0.05 . The collected data were analyzed by SPSS-PC V. 20 software.

\section{Results}

In total, 70 participants were selected for inclusion. The age group of 55-60 years was frequent, and the

Table 3. Demographic characteristics

\begin{tabular}{|c|c|c|c|c|}
\hline \multirow{2}{*}{ Demographic Variables } & \multirow[b]{2}{*}{ Groups } & \multicolumn{2}{|c|}{ Number of People (\%) } & \multirow{2}{*}{$\begin{array}{l}\text { P (Chi-Square Test and } \\
\text { Independent } \mathrm{T})\end{array}$} \\
\hline & & Control Group & Intervention Group & \\
\hline \multirow{4}{*}{ Age status } & $40-44$ & $3(8.6)$ & $2(5.7)$ & \multirow{4}{*}{0.61} \\
\hline & $45-49$ & $9(25.7)$ & $8(22.9)$ & \\
\hline & $50-54$ & $9(25.7)$ & $9(25.7)$ & \\
\hline & $55-60$ & $14(40)$ & $16(45.7)$ & \\
\hline \multirow{2}{*}{ Sex } & Female & $20(57.1)$ & 22 (62.9) & \multirow[b]{2}{*}{0.62} \\
\hline & Male & $15(42.9)$ & $13(37.1)$ & \\
\hline \multirow{4}{*}{ Job } & Employee & $1(2.9)$ & $2(5.7)$ & \multirow{4}{*}{0.1} \\
\hline & Housewife & $19(54.3)$ & $21(60)$ & \\
\hline & Free & $2(5.7)$ & $8(22.9)$ & \\
\hline & Unemployed & $13(37.1)$ & $4(11.4)$ & \\
\hline \multirow{3}{*}{ Admission times } & $1-4$ & $28(80)$ & $25(71.4)$ & \multirow{3}{*}{0.82} \\
\hline & $5-9$ & $7(20)$ & $9(25.7)$ & \\
\hline & $10-15$ & $0(0)$ & $1(2.9)$ & \\
\hline \multirow{3}{*}{ Duration of disease } & $1-4$ & $19(54.3)$ & $18(51.4)$ & \multirow{3}{*}{0.71} \\
\hline & $5-9$ & $4(40)$ & $5(42.9)$ & \\
\hline & $10-15$ & $2(5.7)$ & $2(5.7)$ & \\
\hline \multirow{2}{*}{$\begin{array}{l}\text { Working hours (per } 24 \\
\text { hours a day) }\end{array}$} & $<8$ hours & $25(71.4)$ & $27(77.1)$ & \multirow{2}{*}{0.58} \\
\hline & $>8$ hours & $10(28.6)$ & $8(22.9)$ & \\
\hline
\end{tabular}

Client- Centered Nursing Care 
Table 4. Independent t-test results between the two groups after intervention

\begin{tabular}{cccc}
\hline \multirow{2}{*}{ Study Variables } & \multicolumn{2}{c}{ After Intervention } & \\
\cline { 2 - 3 } & Control Group & Intervention Group & P (Independent T-Test) \\
\hline Systolic blood pressure & $130.77 \pm 10.38$ & $122.74 \pm 10.3$ & $0.002^{* *}$ \\
Diastolic blood pressure & $70.05 \pm 4.96$ & $74.88 \pm 4.52$ & 0.3 \\
\hline Waist & $102.08 \pm 4.57$ & $101.27 \pm 4.56$ & 0.46 \\
\hline Glycosylated hemoglobin & $7.96 \pm 0.48$ & $7.25 \pm 0.7$ & $0.000^{* *}$ \\
\hline High-density lipoprotein & $47.35 \pm 4.64$ & $46.91 \pm 4.85$ & 0.69 \\
\hline Triglyceride & $210.60 \pm 51.7$ & $184.86 \pm 43.15$ & $0.02^{*}$ \\
\hline
\end{tabular}

** Means that the significance level is less than 0.01

Client- Centered Nursing Care

* Means that the significance level is less than 0.05

participants' mean age was $52.72 \pm 11.07$ years. Most participants in this study were females $(60 \%)$, married $(71.45 \%)$ and housewives (57.15\%). Most of the study participants had an elementary level education (94.3\%). More than half of the subjects had a lower level of activity of 8 hours per day $(74.25 \%)$. Average number of hospitalizations due to diabetes in both the groups was between 1- 4 hospitalizations. The mean duration of diabetes in the general sample was $4.8 \pm 2.01$ years. Most of the participants had health insurance status for medical services $(62.85 \%)$ (Table 3$)$.

The effects of intervention: Group differences in change scores and t- test results after the intervention are shown in Table 4.

Independent t- tests showed that, after the intervention, there is a statistically significant difference between the average systolic blood pressure $(\mathrm{P}=0.002)$, glycosylated hemoglobin $(\mathrm{P}=0.000)$, and triglycerides $(\mathrm{P}=0.02)$ in both the experimental and control groups but there was no statistically significant difference in the mean HDL (P $=0.69)$, diastolic blood pressure $(\mathrm{P}=0.3)$ and waist size $(\mathrm{P}=0.46)$.

Group differences in change scores and t-test results before intervention are shown in Table 5. Independent t-tests showed that there was no statistically significant difference between the average systolic blood pressure $(\mathrm{P}=0.17)$, diastolic blood pressure $(\mathrm{P}=0.37)$, waist size $(\mathrm{P}=0.49)$, glycosylated hemoglobin $(\mathrm{P}=0.20)$, HDL ( $P$ $=0.70)$, triglycerides $(\mathrm{P}=0.24)$ in both experimental and control groups before intervention.

Mean scores of metabolic factors before and after intervention in the control group are shown in Table 6.

Pair t- tests showed that in the control group, statistically significant differences were not observed in the mean systolic blood pressure $(\mathrm{P}=0.37)$, diastolic blood pressure $(\mathrm{P}=0.26)$, waist size $(\mathrm{P}=0.42)$, glycosylated

Table 5. Independent t-test results between the two groups before intervention

\begin{tabular}{cccc}
\hline \multirow{2}{*}{ Study Variables } & Control Group & Intervention Group & P \\
\cline { 2 - 4 } & Before Intervention & Before Intervention & 0.17 \\
\hline Systolic blood pressure & $130.69 \pm 10.5$ & $127.34 \pm 9.9$ & 0.37 \\
\hline Diastolic blood pressure & $75.97 \pm 5.01$ & $74.97 \pm 4.4$ & 0.49 \\
Waist & $102.05 \pm 4.61$ & $101.28 \pm 4.56$ & 0.20 \\
\hline Glycosylated hemoglobin & $7.83 \pm 0.69$ & $8.16 \pm 0.64$ & 0.70 \\
\hline High-density lipoprotein & $47.40 \pm 4.55$ & $47.03 \pm 4.38$ & 0.24 \\
\hline Triglyceride & $210.37 \pm 51.49$ & $196.43 \pm 47$ & Client- Centered Nursing Care
\end{tabular}


Table 6. Paired t-test results of control group

\begin{tabular}{cccc}
\hline \multirow{2}{*}{ Study Variables } & \multicolumn{2}{c}{ Control Group } & P (Paired T-Test) \\
\cline { 2 - 4 } & Before Intervention & After Intervention & 0.37 \\
\hline Systolic blood pressure & $130.69 \pm 10.5$ & $130.77 \pm 10.38$ & 0.26 \\
\hline Diastolic blood pressure & $75.97 \pm 5.01$ & $70.05 \pm 4.96$ & 0.42 \\
Waist & $102.05 \pm 4.61$ & $102.08 \pm 4.57$ & 0.37 \\
\hline Glycosylated hemoglobin & $7.83 \pm 0.69$ & $7.96 \pm 0.48$ & 0.78 \\
\hline High- density lipoprotein & $47.40 \pm 4.55$ & $47.35 \pm 4.64$ & 0.11 \\
\hline Triglyceride & $210.37 \pm 51.49$ & $210.60 \pm 51.7$ & Client-Centered Nursing Care
\end{tabular}

hemoglobin $(\mathrm{P}=0.37)$, triglycerides $(\mathrm{P}=0.11), \operatorname{HDL}(\mathrm{P}$ $=0.78)$ before and after the intervention.

Mean scores of metabolic factors before and after intervention in the control group are shown in Table 7.

Pair t- tests showed that after the intervention, there was a statistically significant difference between the average systolic blood pressure $(\mathrm{P}=0.000)$, glycosylated hemoglobin $(\mathrm{P}=0.000)$, and triglycerides $(\mathrm{P}=0.006)$ in experimental groups but there was no statistically significant difference between the mean HDL $(\mathrm{P}=0.73)$, diastolic blood pressure $(\mathrm{P}=0.73)$ and waist size $(\mathrm{P}=$ $0.40)$ after intervention.

\section{Discussion}

The results showed that there was a statistically significant difference in the mean systolic blood pressure, glycosylated hemoglobin and triglyceride between the intervention and control groups. This reflects the effect of the implemented program on the metabolic factors in the intervention group. In context of the effectiveness of discharge planning, Makaryus et al. found that patients did not have sufficient information and knowledge during discharge and less than half of them were able to list the disease diagnosis, drugs' name, main side effects, forgetfulness conditions and dose reduction during discharge. Lack of awareness about these factors influenced the ability of patients to properly follow the medical discharge program (Makaryus \& Friedman 2005). Jack et al. conducted a randomized clinical trial on 749 patients; they found that patients who had received a special discharge program, were better prepared than the control group after discharge (Jack 2009). Furthermore, Rose and Haugen studied the effect of discharge process on patients and nurses. They found that once the discharge process was organized, the understanding of personnel and patients about the discharge process improved (Rose \& Haugen 2010). The results of these studies, such as the present study, emphasized on the positive impact of discharge planning on the outcomes of post- discharge illness and the need to apply it in practice.

Table 7. Paired t-test results of intervention group

\begin{tabular}{cccc}
\hline \multirow{2}{*}{ Study Variables } & \multicolumn{2}{c}{ Intervention Group } & P (Paired T-Test) \\
\cline { 2 - 3 } & Before Intervention & After Intervention & \\
\hline Systolic blood pressure & $127.34 \pm 9.9$ & $122.74 \pm 10.3$ & $\mathrm{P}=0.000^{* *}$ \\
\hline Diastolic blood pressure & $74.97 \pm 4.4$ & $74.88 \pm 4.52$ & $\mathrm{P}=0.73$ \\
\hline Waist & $101.28 \pm 4.56$ & $101.27 \pm 4.56$ & $\mathrm{P}=0.40$ \\
Glycosylated hemoglobin & $8.16 \pm 0.64$ & $7.25 \pm 0.7$ & $\mathrm{P}=0.000^{* *}$ \\
\hline High-density lipoprotein & $47.03 \pm 4.38$ & $46.91 \pm 4.85$ & $\mathrm{P}=0.73$ \\
\hline Triglyceride & $196.43 \pm 47$ & $184.86 \pm 43.15$ & $\mathrm{P}=0.006^{* *}$ \\
\hline
\end{tabular}


Another result of this study was the effect of discharge planning on the reduction of hemoglobin glycosylated levels in type II diabetic patients. In this regard, Ranjbar et al. investigated the effect of remote nursing (mobile application) on controlling metabolic factors and life quality of patients with type 2 diabetes who visited Tehran Diabetes Association. The results showed the mean score of glycosylated hemoglobin significantly decreased in the intervention group in comparison to the control group (Ranjbar 2012). Moreover, the findings of Mousavifar (Musavi far, Zolfaghari \& Faghani 2012) and Zakerimoghadam (Zakerimoghadam et al. 2008), indicated the significant decrease in the mean of glycosylated hemoglobin level in the intervention group in comparison to the control group after intervention, which was in line with the results of the present study. The results referred to the effect of nursing- centered interventions on reducing glycosylated hemoglobin levels in type 2 diabetic patients.

A study by Wexler et al. showed that there was not any statistically significant difference in the mean glycosylated hemoglobin between the critical care group and normal group within the first 3 months $(P=0.2), 6$ months $(\mathrm{P}=0.3)$ and 12 months $(\mathrm{P}=0.5)$ after discharge. On the contrary, there was a statistically significant difference between the mean glycosylated hemoglobin within the first 3 months $(P=0.12), 6$ months $(P=0.004)$ and 12 months $(\mathrm{P}=0.001)$ in the group that recently began insulin therapy after discharge (Wexler et al. 2012). The findings of Wexler's study were not consistent with the results of the present study in which within the first 3 months the effect of regular walking on blood sugar level was not evident as in Wexler's training program. Furthermore, racial differences (Hispanic American), which was one of the risk factors of diabetes, were observed in the participants of the aforesaid research. Since the present research studied both the patient groups, treated with either oral medications or insulin therapy, simultaneously, and not separately, it can be noted that if the present study is conducted separately, it may yield similar results.

Among other findings was that the mean of diastolic blood pressure was not significantly different in the intervention group after intervention than before and in comparison to the control group. It can be indicated that intensive activities or other interventions may be required to make appropriate changes in the diastolic blood pressure. In this regard, Andrews et al. studied 593 patients with type 2 diabetes, who were diagnosed about 5- 6 month earlier, to investigate the effect of diet therapy and physical activity on blood pressure and blood glucose concentration in England. The results showed that blood sugar control with a mean glycosylated hemoglobin of 6.72 and an SD of 1.02 was worse in the control group as compared to other groups within 6 months Moreover, there was an improvement in the body mass index and insulin resistance index between the intervention and control group whereas blood pressure remained the same in all groups (Andrews et al. 2011).

Another finding of the study also showed that the mean of waist size did not show any significant difference in the intervention group after intervention than before and in comparison to the control group. In this regard, Lashgari et al. investigated the effect of remote nursing (telephone follow- up) on metabolic control and life quality of 50 patients with type 2 diabetes in two cities in Kerman. The results showed that there was no significant difference in the mean of decreased fasting blood sugar and BMI after intervention (Lashkari 2011).Therefore, it can be stated that more intensive activities or longer period might be required to make appropriate changes in the mean of waist size.

Franciosi et al. studied the role of self- control blood sugar and special training in 62 diabetic patients. The patients were assigned to normal care group and the group with self- control strategic disease management and were observed for 6 months. After data analysis, the results showed that the level of glycosylated hemoglobin significantly decreased in the intervention group as compared to the control group $(\mathrm{P}=0.04)$. Moreover, the BMI of intervention group improved more than the control group $(P=0.2)$. However, there was not any statistically significant difference in the levels of systolic blood pressure $(\mathrm{P}$ $=0.58)$, diastolic blood pressure $(\mathrm{P}=0.43)$, high- density lipoprotein $(\mathrm{P}=0.02)$, and triglyceride $(\mathrm{P}=0.72)$ (Franciosi et al. 2011). Regarding the fact that although the present study presented the relationship between physical activities and blood sugar levels, the patients did not receive regular exercise program. In addition, the fact that triglyceride level and systolic BP decreased in the current study, it can be concluded that regular exercises and physical activities are necessary for patients in order to change these parameters. Besides, since Franciosi's study lasted for 6 months of follow- ups, the role of time should be noted, in addition to the role of physical activities, as an effective factor on BMI in order to enhance it in their study in comparison to the current study. With respect to the point that high- density lipoprotein level and systolic BP did not change in Franciosi's study like the present study, it can be concluded that more intensive physical activities and longer periods are required to change the levels of these two parameters. 
One of the limitations of the present study was that the participants had different personality traits which might let them react and respond differently to the proposed program, including exercise and diet. This in turn, might affect the severity of their impacts on reducing metabolic factors. Some variables like psychological states, different motivations, environmental factors, and cultural level had different effects on the understanding of individuals about health, learning the trainings and implementing them. This may influence their accuracy in implementing the discharge program. Since the follow- up period was 4 months in the present study, the long- term stability of the effect of intervention remained unknown. In addition, in this study, due to the existence of only one hospital with an internal department, sampling was selected in accessible sampling in order to prevent the bias. Therefore, the random sampling method can be selected in future studies. In addition, the number of samples in this study was 70 , which could be higher in the future studies.

The results of the present study indicated that there was a statistically significant difference in the mean of systolic blood pressure, glycosylated hemoglobin and triglycerides between the intervention (case) and control groups indicating the effect of the implemented program on the aforesaid factors in the intervention group. The overall results showed that the proposed discharge program is effective to improve some metabolic factors in patients with type 2 diabetes. Further studies are recommended according to the limitations and results of the current research.

\section{Acknowledgments}

This article is extracted from the thesis. The ethics committee of Tarbiat Modares University accepted the study(NO. 5274/97). Ethics Committee of Tarbiat Modares University, Tehran, No. 5274/97. The authors thank the participants in this study in order to put the time and effort generously. The authors also appreciate all managers and healthcare facility staffs of Vasei hospital who have helped in the smooth conduction of the research work.

\section{Conflict of Interest}

The authors declared no conflict of interest.

\section{References}

American Diabetes Association., 2006. Diagnosis and classification of diabetes mellitus. Diabetes Care, 29(1), pp. 43-8.

Andrews, R. et al., 2011. Diet or diet plus physical activity versus usual care in patients with newly diagnosed type 2 diabetes: the Early ACTID randomised controlled trial. The Lancet, 378(9786), pp. 129-39. [DOI:10.1016/s0140- 6736(11)60442- x]

Atwal, A., 2002. Nurses' perceptions of discharge planning in acute health care: A case study in one British teaching hospital. Journal of Advanced Nursing, 39(5), pp. 450- 8 [DOI:10.1046/j.1365- 2648.2002.02310.x]

Bauer, M., et al., 2009. Hospital discharge planning for frail older people and their family; Are we delivering best practice: A review of the evidence. Journal of Clinical Nursing, 18(18), pp. 2539- 46. [DOI:10.1111/j.1365-2702.2008.02685.x] [PMID]

Besler, C., Lüscher, T.F. \& Landmesser, U., 2012. Molecular mechanisms of vascular effects of High- density lipoprotein: alterations in cardiovascular disease. EMBO Molecular Medicine, 4(4), pp. 251-68. [DOI:10.1002/emmm.201200224]

Department of Human Services, 1998. Background Paper: A Framework for Effective Discharge December. Victoria: Victoria State Government.

Derosa, G., Salvadeo, S. \& Cicero, A., 2006. Recommendations for the treatment of hypertension in patients with DM: Critical evaluation based on clinical trials. Current Clinical Pharmacology, 1(1), pp. 21-33. [DOI:10.2174/157488406775268237]

Deshpande, A. D., Harris Hayes, M. \& Schootman, M., 2008 Epidemiology of diabetes and diabetes- related complications. Physical Therapy, 88(11), pp. 1254-64. [DOI:10.2522/ ptj.20080020]

Dyck, R. et al., 2010. Epidemiology of diabetes mellitus among First Nations and non- First Nations adults. Canadian Medical Association Journal, 182(3), pp. 249-56. [DOI:10.1503/ cmaj.090846]

Franciosi, M. et al., 2011. ROSES: Role of self- monitoring of blood glucose and intensive education in patients with Type 2 diabetes not receiving insulin: A pilot randomized clinical trial. Diabetic Medicine, 28(7), pp. 789-96. [DOI:10.1111/j.14645491.2011.03268.x]

Jack, B. W., 2009. A reengineered hospital discharge program to decrease rehospitalization. Annals of Internal Medicine, 150(3), pp. 178- 187. [DOI:10.7326/0003- 4819- 150- 3200902030- 00007]

Lashkari, T., 2011. [Effect of tele nursing on metabolic (glycemic) control and quality of life of type 2 diabetic patients in kerman (Persian)] [MSc. thesis]. Kerman: Kerman University of Medical Sciences.

Mahmoudi, A., 2006. [Effects of self care planning on reduction of A1C hemoglobin in adults with diabetes mellitus (Persian)] Medical Science Journal of Islamic Azad Univesity, Tehran Medical Branch, 16(3), pp. 171- 6

Makaryus, A. N. \& Friedman, E. A., 2005. Patients' understanding of their treatment plans and diagnosis at discharge. Mayo Clinic Proceedings, 80(8), pp. 991- 4. [DOI:10.4065/80.8.991] 
Marks, L., 1994. Seamless care or patchwork quilt: Discharging patients from acute hospital care. London: King's Fund Institute.

Musavi Far, A., Zolfaghari, M. \& Faghani, H., 2012. [The impact of nurse short message services and telephone follow- ups on diabetic adherence (Persian)]. Iranian Journal of Diabetes and Lipid Disorders, 10(4), pp. 407- 18.

Nalysnyk, L., Hernandez Medina, M. \& Krishnarajah, G., 2010. Glycaemic variability and complications in patients with diabetes mellitus: evidence from a systematic review of the literature. Diabetes, Obesity and Metabolism, 12(4), pp. 288-98. [DOI:10.1111/j.1463- 1326.2009.01160.x] [PMID]

Philbin, E. F., 1999. Comprehensive multidisciplinary programs for the management of patients with congestive heart failure. Journal of General Internal Medicine, 14(2), pp. 130-5. [DOI: 10.1046/j.1525- 1497.1999.00291.x] [PMID]

Phillips, C. O. et al., 2004. Comprehensive discharge planning with postdischarge support for older patients with congestive heart failure. JAMA, 291(11), p. 1358. [DOI:10.1001/ jama.291.11.1358]

Ranjbar, A., 2012. [Study of the effect of telenursing (call phone program) on metabolic control and quality of life in patients of type 2 diabetes referred to the diabetic association in Tehran (Persian)] [MSc. thesis]. Kerman: Kerman University of Medical Science.

Rorden, J. W. \& Taft, E., 1990. Discharge planning guide for nurses. Philadelphia: Saunders Company.

Rose, K. E., \& Haugen, M. B., 2010. Discharge planning: Your last chance to make a good impression. Medsurg Nursing, 19(1), pp. 47- 53. [PMID]

Taylor, C., 2003. Fundamentals of nursing: Concepts, process, and practice (1) [Z. Safavi Bayat, Persian trans]. Tehran: Boshra Publishing.

Watts, R. \& Gardner, H., 2005. Nurses' perceptions of discharge planning. Nursing \& Health Sciences, 7(3), pp. 175- 83. [DOI:10.1111/j.1442- 2018.2005.00229.x] [PMID]

Wexler, D. J. et al., 2012. Impact of inpatient diabetes management, education, and improved discharge transition on glycemic control 12 months after discharge. Diabetes Research and Clinical Practice, 98(2), pp. 249-56. [DOI:10.1016/j.diaa bres.2012.09.016]

World Health Organization., 2014. Ten facts about diabetes. Geneva: World Health Organization.

Yam, C. H., et al., 2010. Measuring and preventing potentially avoidable hospital readmissions: A review of the literature. Hong Kong Medical Journal, 16(5), pp. 383-9. [PMID]

Zakerimoghadam, M., et al., 2008. [Effect of nurse- led telephone follow ups (tele- nursing) on diet adherence among type 2 diabetic patients (Persian)]. Journal of Hayat, 14(2), pp. 63- 71. 